\title{
Comparison of ornidazole and tinidazole in single-dose treatment of trichomoniasis in women
}

\author{
LARS HILLSTRÖM ${ }^{1}$, LARS PETTERSSON ${ }^{1}$, AND EINAR PÁLSSON², \\ From the Department of Dermatology and Venereology ${ }^{1}$, District General Hospital, Gävle, and the \\ Department of Obstetrics and Gynaecology ${ }^{2}$, District General Hospital, Nacka, Sweden
}

SVEN OLOV SANDSTRÖM

From the Department of Obstetrics and Gynaecology, District General Hospital, Västervik, Sweden

SUMMARY A comparison is made between oral ornidazole in a single $1.5 \mathrm{~g}$ dose and tinidazole given in a $2 \mathrm{~g}$ dose using a double-blind technique. All the 45 women with Trichomonas vaginalis infection who were treated with ornidazole were cured. In the tinidazole-treated group 41 out of 43 women had negative cultures after treatment. Tolerance was good in both groups.

\section{Introduction}

A study of ornidazole*, a new antiprotozoal compound for treating Trichomonas vaginalis infection, has recently been made (Sköld et al., 1977). In the study $2 \mathrm{~g}$ of ornidazole was given orally as a single dose. The cure rate was $100 \%$, but eight out of the 20 women reported pronounced side effects.

A high cure rate with a single dose of $2 \mathrm{~g}$ ornidazole has been reported recently in other clinical trials (Gaudin, 1976; Nygaard et al., 1977). Pharmacological studies (Sköld et al., 1977) showed that a single dose of $2 \mathrm{~g}$ orally results in plasma levels of unchanged ornidazole, which are well above the minimum inhibitory concentration (MIC) for at least 36 hours after administration, with peak levels five to eight times higher than the MIC.

In a recent study (Matheson et al., 1977) administration of a single oral $1.5 \mathrm{~g}$ dose resulted in sufficiently high plasma concentrations to obtain a good trichomonicidal level.

The aim of the current study was to find out whether it is possible to reduce the side effects of orinidazole by giving a lower dose and at the same time maintain a satisfactory result. During the last year, other treatments using short, high-dose schedules have been introduced-for example, treatment with $2 \mathrm{~g}$ tinidazole (Fasigyn $\left.{ }^{\circledR}\right)$. We thus decided to compare the effect and tolerance of $1.5 \mathrm{~g}$ ornidazole with $2 \mathrm{~g}$ tinidazole administered orally in a double-blind study.

*Ro 7-0207 (Tiberal®, Kolpicid®). F. Hoffman-La Roche \& Co. Ltd, Basle, Switzerland

Address for reprints: L. Hillström, Department of Dermatology and Venereology, District General Hospital, Gävle, Sweden

Received for publication 6 January 1977

\section{Material and methods}

The trial was conducted at two outpatient departments for gynaecological diseases and one outpatient department for venereal diseases. A total of 90 consecutive female patients with $T$. vaginalis infection demonstrated by direct microscopical examination were studied. Samples for culture on Diamond's medium were taken at each visit.

All women were otherwise healthy and none was pregnant. Their ages ranged between 14 and 71 years, with a mean of 33 years. Eight of the patients had been treated with ampicillin for gonococcal infection about a week before the study, and 11 had been treated for $T$. vaginalis infections at least two months before entering the study. At the clinical examination the women were asked about subjective symptoms, such as itching, irritation, and increased vaginal discharge and objective signs such as colpitis and excess discharge were registered. The duration of symptoms varied between a couple of days and years. Five patients had no subjective symptoms at all.

Forty-five women were treated with three tablets of $500 \mathrm{mg}$ ornidazole (equivalent to $17-35 \mathrm{mg} / \mathrm{kg}$ bodyweight) and one placebo tablet. The remaining 45 women were given four tablets of $500 \mathrm{mg}$ tinidazole (equivalent to $26-43 \mathrm{mg} / \mathrm{kg}$ body weight). The tablets were to be taken at bed-time. The sexual partners ( 27 in the ornidazole group and 25 in the tinidazole group) received corresponding treatment. The tablets looked identical and each dose was separately packed, numbered, and coded. Neither staff nor patients knew who received which treatment until the trial finished. The women were allocated to the two treatment groups using random sampling 
numbers. These two groups did not differ as regards age distribution, duration of symptoms, or type of contraceptives. Follow-up visits, including culture and a note of drug tolerance, took place about one week and one month after treatment.

\section{Results}

Of the 90 women admitted to the trial, one did not return for follow-up and one was regarded as having been over-diagnosed. They were both excluded from the trial; both had received tinidazole.

Table Results of follow-up examinations

\begin{tabular}{|c|c|c|c|c|c|c|}
\hline \multirow[b]{2}{*}{ Infection } & \multicolumn{2}{|c|}{ Before treatment } & \multicolumn{2}{|c|}{ First control } & \multicolumn{2}{|c|}{ After one month } \\
\hline & $\begin{array}{l}\text { Orni- } \\
\text { dazole } \\
n=45\end{array}$ & $\begin{array}{l}\text { Tini- } \\
\text { dazole } \\
n=43\end{array}$ & $\begin{array}{l}\text { Orni- } \\
\text { dazole } \\
n=45\end{array}$ & $\begin{array}{l}\text { Tini- } \\
\text { dazole } \\
n=43\end{array}$ & $\begin{array}{l}\text { Orni- } \\
\text { dazole } \\
n=42\end{array}$ & $\begin{array}{l}\text { Tini- } \\
\text { dazole } \\
n=40\end{array}$ \\
\hline$T$. vaginalis & 45 & 43 & 0 & 2 & 1 & 3 \\
\hline
\end{tabular}

As the Table shows, all 45 women treated with ornidazole had negative $T$. vaginalis cultures at the first follow-up, while two out of 43 women treated with tinidazole still had positive cultures. These two patients were again treated, this time with ornidazole, and one was successfully cured.

Subjective discomforts, such as itching, irritation, and discharge, improved after two to three days in both treatment groups. Also the objective signs of infection had disappeared in most of the patients at the first follow-up visit; some other infection (due to for example, Candida albicans, Haemophilus vaginalis, or Neisseria gonorrhoeae) was usually present in those patients who still had symptoms.

Side effects were reported by six out of the 45 patients treated with ornidazole. In one case vertigo occurred one hour after taking the tablets; one woman complained of gustatory changes, and the other four of fatigue the day after treatment.
Among the patients treated with tinidazole, discomfort was reported by nine of 43 patients. Three women complained of gustatory changes, and other discomforts reported were loose stools and insomnia. All side effects were of a mild and transient character, and none required treatment.

\section{Discussion}

In this and other studies (Gaudin, 1976; Nygaard et al., 1977; Sköld et al., 1977) ornidazole was proved to be a safe and easily administered drug in the treatment of $T$. vaginalis infection. The single dose administration is an advantage in the treatment of outpatients, as such a regimen is convenient for patients and for their partners.

In the current study the cure rate after one week was $100 \%$ for the patients treated with ornidazole, and $95 \%$ for the patients treated with tinidazole. In the ornidazole group reinfection occurred in only one of the 42 patients who attended the follow-up one month later. This finding indicates the importance of treating the partners, as well as the patients suffering from $T$. vaginalis infection.

Pronounced side effects occurred in earlier studies of ornidazole given as a single $2 \mathrm{~g}$ dose (Nygaard et al., 1977; Sköld et al., 1977). A reduction of the dose to $1.5 \mathrm{~g}$ reduced the side effects, and did not affect the cure rate, which was maintained at a high level.

\footnotetext{
References

Gaudin, G. (1976). L'emploi du Tiberal ${ }^{\circledR}$ dans les vaginites à trichomonas en prise unique. Schweizerische Rundschau fuer Medizin (Praxis), 65, 626-627.

Matheson, I., Hernborg Johannessen, K., and Bjørkvoll, B. (1977). Plasma levels of ornidazole after a single oral dose of $1.5 \mathrm{~g}$. British Journal of Venereal Diseases, 53, in press.

Nygaard, B., Kjaersgaard, H., Korner, B., and Hammer Jensen, R. (1977). Engangsbehandling med ornidazol (Tiberal $($ ) og syv dages behandling med metronidazol (Flagyl $($ ) ved vaginal trichomoniasis. Ugeskrift for Laeger, 139, 524-526.

Sköld, M., Gnarpe, H., Hillström, L. (1977). Ornidazole: A new antiprotozoal compound for treatment of Trichomonas vaginalis infection. British Journal of Venereal Diseases, 53, 44-48.
} 